\title{
Multiple sclerosis in island populations: prevalence in the Bailiwicks of Guernsey and Jersey
}

\author{
G Sharpe, S E Price, A Last, R J Thompson
}

\begin{abstract}
The aim of this study was to establish for the first time the prevalence of multiple sclerosis in the Bailiwicks of Guernsey and Jersey, as representing the most southerly part of the British Isles. All patients with multiple sclerosis in the Channel Islands resident on prevalence day were identified by contacting all medical practices, Multiple Sclerosis, and Action Research for Multiple Sclerosis societies by letter and visits. The crude overall prevalence rates were $113 / 100000(95 \%$ confidence interval (95\% CI) 90.3-135.7) and 86.7/100 000 (95\% CI 63.3-110.0) for the Bailiwicks of Jersey and Guernsey respectively. When standardised to the age and sex structure of a previously reported Northern Ireland population the standardised prevalence ratios were $120 \cdot 2 / 100000(95 \%$ CI 96.0-144.3) for Jersey and 95.6/100 000 (95\% CI 69.9-121.3) for the Bailiwick of Guernsey. When compared with recent studies in the northern United Kingdom the prevalence rates for multiple sclerosis in the Channel Islands lend some support to the proposed latitudinal gradient in the British Isles although the standardised prevalence ratio in the Bailiwick of Jersey is similar to those found in recent studies of southern Britain. The standardised prevalence rates of probable and definite multiple sclerosis for the male populations were $37 \cdot 3 / 100000(95 \%$ CI $17 \cdot 9-56 \cdot 7)$ for the Bailiwick of Guernsey and $45 \cdot 5 / 100000(95 \%$ CI $26 \cdot 3-64 \cdot 7)$ for the Bailiwick of Jersey whereas the standardised prevalence rates for the female populations were $97.5 / 100000 \quad(95 \% \quad C I$ 73.9-143.5) and $139 \cdot 5 / 100000$ (95\% CI $112 \cdot 6-181 \cdot 2)$ respectively. Thus there is a striking and unexplained $43 \%$ higher prevalence of probable and definite multiple sclerosis in the female population of Jersey compared with that of the Bailiwick of Guernsey. This seems to be due to an unusually low prevalence of the disease among the female population of the Bailiwick of Guernsey compared with that of the United Kingdom mainland.
\end{abstract}

(F Neurol Neurosurg Psychiatry 1995;58:22-26)

Keywords: multiple sclerosis; prevalence survey

Multiple sclerosis is a common cause of seri- ous neurological disability in young adults; it affects some 60000 people in the United Kingdom and perhaps two million people worldwide. ${ }^{1}$ The disease shows an unusual geographical distribution in becoming commoner with increasing distance from the Equator in both the northern and southern hemispheres. ${ }^{2}$ There is evidence for a similar geographical gradient in the British Isles. ${ }^{2}$ Different studies have reported multiple sclerosis to be 1.9 to 3.1 times commoner in women than men and to have a peak age of onset of about 30 years, being rare in childhood and after the age of $50 .^{2}$ The clinical features, sex ratio, and age specific incidence curves for multiple sclerosis are similar whatever the underlying frequency of disease, suggesting the same worldwide aetiology. ${ }^{2}$

Among the many epidemiological surveys of multiple sclerosis in the past 40 years, several intriguing reports have studied the prevalence of the disease in geographically defined island populations. The Orkney and Shetland islands have the highest prevalence of the disease ever recorded-namely, 309 and 184 per 100000 respectively. $^{3}$ The prevalence on Sardinia ${ }^{4}$ and Sicily ${ }^{5}$ has been reported to be over 45 per 100000 , whereas on nearby Malta the prevalence is tenfold lower. ${ }^{6}$ Clustering of cases of multiple sclerosis has been recorded on Orkney ${ }^{7}$ and on the small island of Key West off the coast of Florida. ${ }^{8}$ An "epidemic" of multiple sclerosis in the Faroes after occupation by British troops has been proposed, ${ }^{9}$ and a similar rise in prevalence after troop incursions has been claimed on Orkney, ${ }^{10}$ Iceland, ${ }^{11}$ and Sardinia. ${ }^{12}$ That the incursions caused the apparent increase in the prevalence of multiple sclerosis in these situations has in most cases been disputed. ${ }^{2}$

The Channel Islands lie 70-100 miles south of the coast of England between $49^{\circ}$ and $50^{\circ}$ latitude and about $10-30$ miles west of the French coast, with the nearest island (Alderney) only eight miles from the Cotentin peninsula. The British Channel Islands are not part of the United Kingdom, but are crown dependencies allied to the English crown since the Norman invasion. They represent the most southerly part of the British Isles. These Islands were invaded by Germany in June and July 1940 and liberated in May $1945^{13}$ and were the only part of the British Isles occupied in the second world war. The islands are divided into the Bailiwicks of Guernsey and Jersey. The Bailiwick of Guernsey consists of Guernsey, Alderney, Sark, and other small islands, and 
the Bailiwick of Jersey contains several small uninhabited islands with only Jersey itself populated. Health care services in the two Bailiwicks are independent of the NHS and of each other. Also, as a popular holiday destination and an attractive residential choice due to favourable tax concessions, the Channel Islands are not as geographically isolated as some other islands-for example, Orkney and Shetland. ${ }^{7}$ No previous survey of the prevalence of multiple sclerosis in the Channel Islands has been carried out. The present study was undertaken to determine the prevalence of multiple sclerosis in the two Bailiwicks in the light of recent estimates of the prevalence of multiple sclerosis in southern Britain, ${ }^{14-18}$ and the proposed north-south gradient in the prevalence of multiple sclerosis in the British Isles. ${ }^{2}$

\section{Methods}

CASE ASCERTAINMENT

A list of potential patients with multiple sclerosis was compiled with information obtained from several sources, as the Southampton study ${ }^{16}$ had shown the value of this approach. The medical practitioners from both Bailiwicks were a major source of information. We also received help from the Multiple Sclerosis and Action Research for Multiple Sclerosis (ARMS) Societies in both sets of islands, and also from the hyperbaric oxygen unit on Guernsey. The nearest British major referral centre for neurology is the Wessex Neurological Centre at Southampton; this has become the predominant specialist referral centre for the Channel Islands but many patients have been seen elsewhere. Also, a consultant neurologist from Southampton visits Jersey regularly. Consultant neurologists at the Wessex Neurological Centre were therefore approached.

From these sources we compiled a provisional list of potential cases of multiple sclerosis covering the Bailiwicks of Guernsey and Jersey. This was then used for a more detailed study. Medical practitioners were contacted again by letter and requested to provide details (name, date of birth, sex, and whether the patient was aware of the diagnosis) of any patients under their care with multiple sclerosis who were alive and resident on the Channel Islands on prevalence day.

After this, consent was sought to approach the patient and obtain a venous blood sample for a separate genetic study. Prevalence days were 10 March 1991 for the Bailiwick of Jersey and 21 April 1991 for the Bailiwick of Guernsey. These days were chosen to coincide with local census days on each set of islands. (The difference between the two prevalence days is not considered relevant to the results of the study.) Further letters were sent to doctors not replying to initial enquiries and non-responders were contacted by phone, or personal visit, or both.

CLASSIFICATION OF PATIENTS

The provisional list of possible cases of multi- ple sclerosis was then subjected to careful investigation. Sufficient clinical details to allow classification by both the criteria of Poser et al ${ }^{19}$ and of Allison and Millar ${ }^{20}$ were sought. This was obtained either by three authors (GS, SEP, AL) being allowed access to the patients' notes or by the medical practitioners filling in a detailed questionnaire. The hospital notes of patients who had attended the Wessex Neurological Centre were also studied. Local Multiple Sclerosis Societies were requested to ask their members to supply details of place of birth and age of onset of the disease. Forty eight patients on Jersey and 36 on Guernsey and Alderney who volunteered had a venous blood sample taken by a member of the team.

\section{STATISTICAL ANALYSIS}

Population statistics were obtained from the census taken on prevalence day on Jersey, ${ }^{21}$ Guernsey, ${ }^{22}$ and Alderney. ${ }^{23}$ No formal census data are gathered on Sark and it was estimated that 560 people were resident there: we did not find a single case of multiple sclerosis in this population and have excluded it from further analysis. To allow for differences between islands in age and sex structure and to allow comparison with published work, all crude prevalence data have been standardised against the 1961 Northern Ireland population $^{24}$ by two different methods. The indirect method was used to calculate standardised prevalence ratios with $95 \%$ confidence intervals (95\% CIs) for each Bailiwick. To test the significance of differences in prevalence between the Islands and the 1961 Northern Ireland population for specific age groups, it was assumed that the observed number of cases follows a Poisson distribution with a mean equal to the expected number of cases under the standard prevalence rates. The direct method was used to calculate age standardised prevalence rates for each Bailiwick and the difference in standardised rates between islands, along with $95 \%$ CIs. ${ }^{25}$

\section{Results}

The provisional register of potential patients with multiple sclerosis in the Channel Islands contained 193 names; of these 45 were eventually excluded because they were not resident on prevalence day $(n=8)$, or because the diagnosis of multiple sclerosis could not be confirmed $(n=9)$, or the person was not traced $(n=15)$. Additionally, one patient was registered with more than one practice and six were registered under both married and maiden names. Of the 45 patients 21 came from Jersey and 24 from Guernsey. A diagnosis of multiple sclerosis was accepted if it was confirmed by information from the patient's medical practitioner or from the medical notes. Some excluded patients had other diagnoses-for example, hereditary spastic paraparesis (which can mimic multiple sclerosis) $(n=4)$, Parkinson's disease $(n=1)$, or benign intracranial hypertension $(n=1)$. Others had suspicious symptoms but no signs 
$(n=4)$. Every medical practice in the Bailiwicks of Guernsey and Jersey responded to this survey. Table 1 shows the number of resident cases found in each Bailiwick on prevalence day together with the recorded populations from the official census returns. It also shows the 53 patients from the Bailiwick of Guernsey and the 95 patients from Jersey classified according to the criteria of Allison and Millar $^{20}$ and those of Poser et al. ${ }^{19}$ Ninety four per cent of the patients of the Bailiwick of Guernsey and $88 \%$ of the patients on Jersey came under the "probable and possible" Allison and Millar classification ${ }^{20} ; 85 \%$ of the patients of the Bailiwick of Guernsey population and $88 \%$ of the Jersey population were fully classifiable under the system of Poser et al. ${ }^{19}$ Of those who could not be readily classified under the Poser system 10 could not be categorised even with full clinical details (mainly those with progressive spinal cord disease) and with the remainder $(n=9)$ we were unable to attain sufficient clinical details to make classification possible. The four patients from Alderney in the Bailiwick of Guernsey (one male and three female) were all in the clinically definite category. Of the total identified cases of multiple sclerosis, $19(13 \%)$ had a positive family history but in only $5 \%$ of cases was a first degree relative also affected. Only one affected sib pair was found on Guernsey, and one patient with a normal twin was resident on Jersey, as was one male patient with a sister not resident in the Channel Islands but being investigated for the disease elsewhere.

Table 2 shows the overall crude preva-

Table 1 Clinical classification of patients with multiple sclerosis on the Channel Islands

\begin{tabular}{|c|c|c|}
\hline & \multicolumn{2}{|l|}{ Bailiwick } \\
\hline & $\begin{array}{l}\text { Guernsey } \\
\text { (Population } 61 \text { 624) }\end{array}$ & $\begin{array}{l}\text { Fersey } \\
\text { (Population } 84 \text { 082) }\end{array}$ \\
\hline $\begin{array}{l}\text { Total cases } \\
\text { recorded } \\
\text { Female:male sex } \\
\text { ratio }\end{array}$ & $\begin{array}{l}53 \\
2 \cdot 6: 1\end{array}$ & $\begin{array}{l}95 \\
3 \cdot 1\end{array}$ \\
\hline $\begin{array}{l}\text { Alison and Millar } \\
\text { Probable } \\
\text { Possible } \\
\text { Early }\end{array}$ & $\begin{array}{l}\text { ieria }^{20} \text { : } \\
42 \\
8 \\
3\end{array}$ & $\begin{array}{r}78 \\
6 \\
11\end{array}$ \\
\hline $\begin{array}{l}\text { Poser et al criteria' } \\
\text { CDMDS } \\
\text { LSDMS } \\
\text { CPMS } \\
\text { LSPMS } \\
\text { Unclassifiable }\end{array}$ & $\begin{array}{r}40 \\
1 \\
2 \\
2 \\
8\end{array}$ & $\begin{array}{r}80 \\
1 \\
1 \\
2 \\
11\end{array}$ \\
\hline
\end{tabular}

CDMS = Clinically definite multiple sclerosis; LSDMS = laboratory supported definite multiple sclerosis; CPMS = Clinically probable multiple sclerosis; LSPMS = Laboratory supported probable multiple sclerosis; Unclassifiable = Unclassifiable with Poser et al criteria. lences and the standardised prevalence ratios with the populations of the two Bailiwicks age and sex standardised against the 1961 Northern Ireland population. ${ }^{24}$ Also shown are the figures from other recent studies in the south of the United Kingdom. ${ }^{14-18}$ The census reports showed that the age and sex structures of the populations of the two Bailiwicks were almost identical (results not presented). Further analysis was confined to patients with multiple sclerosis who came into the "definite and probable" categories of the criteria of Poser et al. ${ }^{19}$ These comprised $85 \%$ of the patients from Guernsey and Alderney and $88 \%$ of the patients from Jersey. The figure shows the age specific prevalence of probable and definite cases of multiple sclerosis for both sets of islands compared with that of the Northern Ireland population. ${ }^{24}$ Whereas the overall shape of the distribution is similar in all three cases (especially at earlier ages), both Bailiwicks have higher prevalences in older age groups than the original Northern Ireland study. ${ }^{20}$ At ages 60 and older, 8.35 cases would have been expected in Jersey by applying the prevalence of the standard populations, but 18 cases were found. This excess was highly significant $(p=0.003)$. At these age groups in Guernsey and Alderney, 12 cases were observed compared with 6.95 expected (test for excess $p=0.5$ ). Table 3 shows the crude prevalence rates and the age adjusted rates for male and female cases in the Channel Islands. Surprisingly, whereas the male populations only showed a difference of $8 \cdot 2$ cases per 100000 males between the two

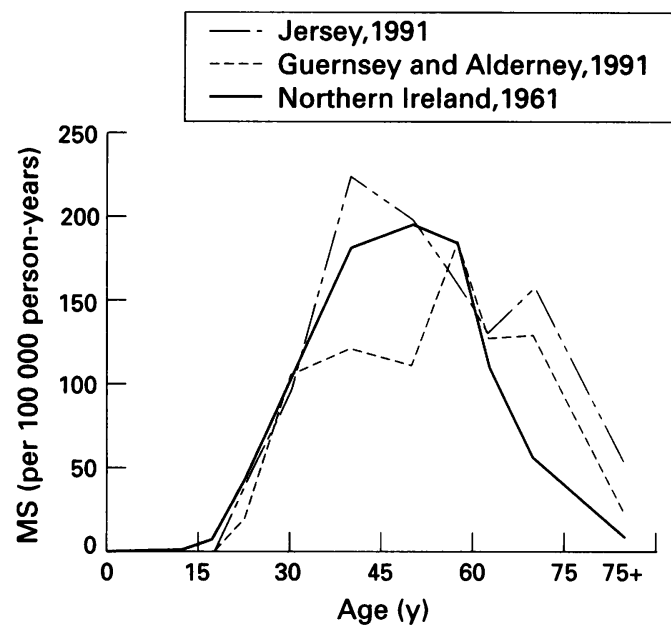

Age specific prevalence of probable and definite cases of multiple sclerosis (MS).

Table 2 Comparison of Channel Islands study with other recent south British studies

\begin{tabular}{lllllll}
\hline & fersey 1991 & $\begin{array}{l}\text { Guernsey and } \\
\text { Alderneyt 1991 }\end{array}$ & Cambridge 1990 & $\begin{array}{l}\text { Southampton and } \\
\text { SWHHA 1987 }\end{array}$ & $\begin{array}{l}\text { SE London } \\
\text { (Sutton) 1985 }\end{array}$ & $\begin{array}{l}\text { SE Wales } \\
1985\end{array}$ \\
\hline No of cases & 95 & 53 & 374 & 411 & 195 & 441 \\
Population & 84082 & 61164 & 288410 & 411000 & 169600 & 376710 \\
Crude prevalence rates/100 000 & $113(90 \cdot 3-135 \cdot 7)$ & $86.7(63 \cdot 3-110 \cdot 0)$ & $130(117-143)$ & $99(89-109)$ & $115(99-131)$ & $117(106-128)$ \\
*SPR & $120 \cdot 2(96 \cdot 0-144 \cdot 3)$ & $95 \cdot 6(69 \cdot 9-121 \cdot 3)$ & $121(108-133)$ & $115(108-133)$ & $129(111-127)$ & $139(126-150)$ \\
\hline
\end{tabular}

* Standardised prevalence ratio. The figure shown is the one that would have been obtained if these populations had the same age and sex structure as the population surveyed in Northern Ireland $1961^{20}$ and taking the prevalence found in that study as $=100 . .^{14}$ 
Table 3 Age standardised prevalence rates of probable and definite multiple sclerosis in male and female populations in the Channel Islands

\begin{tabular}{|c|c|c|}
\hline & Crude prevalence & $\begin{array}{l}\text { Age standardised } \\
\text { prevalence }\end{array}$ \\
\hline \multicolumn{3}{|l|}{ Males: } \\
\hline Bailiwick of Guernsey & $47 \cdot 6 / 100000$ & \multirow{2}{*}{$\begin{array}{l}37 \cdot 3 / 100000 \\
(95 \% \text { CI } 17 \cdot 9-56 \cdot 7) \\
45 \cdot 5 / 100000 \\
(95 \% \text { CI } 26 \cdot 3-64 \cdot 7)\end{array}$} \\
\hline Bailiwick of Jersey & $53 \cdot 8 / 100000$ & \\
\hline \multicolumn{3}{|l|}{ Females: } \\
\hline Bailiwick of Guernsey & $110 \cdot 2 / 100000$ & \multirow{2}{*}{$\begin{array}{l}97 \cdot 5 / 100000 \\
(95 \% \text { CI } 73 \cdot 9-143 \cdot 5) \\
139 \cdot 5 / 100000 \\
(95 \% \text { CI } 112 \cdot 6-181 \cdot 2)\end{array}$} \\
\hline Bailiwick of Jersey & $162 \cdot 0 / 100000$ & \\
\hline
\end{tabular}

‡To Northern Ireland 1961 crude prevalence $=65 \cdot 8 / 100000$ (male) 94.6/100 000 (female). Difference in age standardised prevalence between two Bailiwicks: male $=8 \cdot 2$ cases $/ 100000$. $(19 \cdot 8$ to $36 \cdot 1), \mathrm{p}$ value for difference $=0.6$; female $=42$ cases $/ 100000-6.4$ to $90 \cdot 3) \mathrm{p}=0.09$.

Bailiwicks (95\% CI $19 \cdot 8-36 \cdot 1, \mathrm{p}=0 \cdot 6$ ), the female populations showed a profound difference, with a large excess of 42 cases per 100000 of the female population seen on Jersey $(95 \% \mathrm{CI}-6 \cdot 4$ to $90 \cdot 3, \mathrm{p}=0 \cdot 09)$. The mean age of male patients with multiple sclerosis was 49.6 for the Bailiwick of Guernsey and 53.6 for Jersey and the corresponding mean ages for female patients were $46 \cdot 1$ and 43.8 respectively. We were able to establish the year of onset of the disease in $46(87 \%)$ of the patients on Guernsey and Alderney and in $69(73 \%)$ of the patients on Jersey. There was no evidence of clustering by year of onset among these patients, as claimed in a previous Orkney study. ${ }^{7}$ We were unable to find reliable information on the prevalence of multiple sclerosis in the Channel Islands before the second world war and in only one patient in this study was the onset of the disease before 1940. Among the patients in whom age of onset was established there was a tendency for it to be earlier in the female (but not male) patients on Guernsey than in those on Jersey. We were able to establish the place of birth in $40(75 \%)$ of the 53 patients in the Bailiwick of Guernsey and in $57(60 \%)$ of the 95 patients on Jersey. Of these, $70 \%$ of the patients on Guernsey and Alderney and $58 \%$ of the patients on Jersey were native to their respective islands. From the census returns ${ }^{21-23} 65 \%$ of the total population of Guernsey and Alderney were born on the islands with $77 \%$ of the remaining $35 \%$ of population originating elsewhere in the British Isles. On Jersey $52 \%$ of the total population are native with $76 \%$ of the remaining $48 \%$ coming from elsewhere in the British Isles.

\section{Discussion}

The present study is the first survey of the prevalence of multiple sclerosis in the Channel Islands. The methods used were similar to other recent studies in southern England. ${ }^{1618}$ Because of the geographically circumscribed island nature of the populations studied, the many sources of case identification, and the high response rate to inquiries, we believe that the estimate of numbers of patients in the Bailiwicks of Guernsey and Jersey is accurate. As the Channel Islands lie 70-100 miles south of the United Kingdom mainland, information on the prevalence of multiple sclerosis there is of value in deciding whether a latitudinal gradient in the prevalence of the disease exists in the British Isles as seems to occur on a worldwide basis. ${ }^{2}$ Whereas the current age and sex standardised prevalence ratio of $120 \cdot 2$ (if 100 $=$ Northern Ireland 1961) in the Bailiwick of Jersey is little different from the standard prevalence ratios in Southampton (115), ${ }^{16}$ Cambridge (121), ${ }^{18}$ and Sutton (129), ${ }^{14}$ it is considerably lower than the most recent survey of north east Scotland (221). ${ }^{26}$ The Bailiwick of Guernsey has an even lower prevalence ratio of $95 \cdot 6$. These figures overall would therefore lend at least some support to the proposed latitudinal gradient in prevalence of multiple sclerosis in the British Isles, ${ }^{2}$ at least between northern and southern Britain. Between the two Bailiwicks the age specific prevalence profiles of multiple sclerosis for probable or definite cases show significantly higher prevalence in older age groups $(60+)$ on both sets of islands (Jersey, $p=$ 0.003; Guernsey, $p=0.5$ ) than in the Northern Ireland population, which presumably reflects improved longevity of patients in the 30 years since that study was performed. ${ }^{24}$ The familial incidence of multiple sclerosis in the Channel Islands also seems to be lower than in some surveys ${ }^{2}$ and only seven (5\%) patients have a first degree relative also affected.

The striking finding in the present study is the unexpectedly high prevalence of female patients with probable or definite multiple sclerosis on Jersey compared with the Bailiwick of Guernsey $(139.5 / 100000 v$ $97 \cdot 5 / 100000$ ), which largely accounts for the difference in overall prevalence between the two populations (table 3). The female:male ratios of the general population of the two Bailiwicks are almost identical (1:1.07 and $1: 1 \cdot 05)$. Because the methods of ascertainment were the same on both sets of islands and because only probable or definite cases were included, this difference seems to be real. The observed prevalence per 100000 females on Jersey is in line with that seen in recent surveys of southern Britain. ${ }^{14-18}$ Thus the female prevalence rate in the Bailiwick of Guernsey should be regarded as unusually low compared with mainland Britain. There is a dearth of prevalence data for nearby France, although a recent paper has quoted a figure of $40 / 100000 .{ }^{27}$ We are unaware of any established difference in the genetic make up of the populations of the two Bailiwicks and it is difficult to see why such factors should only apply to the female and not the male population.

The first two authors made equal contributions to this work We are grateful to the medical practitioners, the officers an members of the Multiple Sclerosis and ARMS Societies, and especially the patients in both the Bailiwicks of Guernsey and Jersey for taking part in this study. We also acknowledge the help of the neurologists at the Wessex Neurological Centre We thank the States of Guernsey for providing the Third Guernsey Fellowship (GS) via the Wessex Medical Trust. This work was also supported by the Multiple Sclerosis Society of Great Britain and Northern Ireland. SEP is an MRC Training Fellow. A Shiel (MRC Epidemiology Unit) is thanked for expert statistical advice. F Lander, $\mathrm{K}$ Debrah, J Dean, B Morgan, and S Linham are thanked for help at various stages of this project. 
1 Compston DAS. The dissemination of multiple sclerosis fournal of the Royal College of Physicians of London 1990 24:207-18.

2 Martyn CN. The epidemiology of multiple sclerosis. In Matthews WP, ed. McAlpine's multiple sclerosis. London: Churchill Livingstone, 1991:3-212.

3 Poskanzer DC, Prenney LB, Sheridan JL, Kandy JY. Multiple sclerosis in the Orkney and Shetland Islands. f Epidemiol Community Health 1980;34:229-39.

4 Rosali G, Aiello A, Pirastow MI, et al. Sardinia, a high risk area for multiple sclerosis: a prevalence and incidence study in the district of Alghero. Ann Neurol 1987;21: $190-4$.

5 Dean G, Grimaldi G, Kelly R, Karhausen L. Multiple sclerosis in southern Europe I. Prevalence in Sicily in 1975. F Epidemiol Community Health 1979;33:107-10

6 Vassallo L, Elian M, Dean G. Multiple sclerosis in Southern Europe II. prevalence in Malta 1978. f Epidemiol Community Health 1979;33:110-3.

7 Poskanzer DC, Walker AM, Prenny LB, Sheridan JL. The aetiology of multiple sclerosis in temporal-spatial clustering indicating two environmental exposures before onset. Neurology 1981;31:708-13.

8 Sheremata WA, Poskanzer DC, Withum DG, MacLeod CL, Whiteside ME. Unusual occurrence on a tropical island of multiple sclerosis. Lancet 1985;ii:618.

9 Kurtzke J, Hullested K. Multiple sclerosis in the Faroe Islands III. An alternative assessment of the three epidemics. Acta Neurol Scand 1987;76:317-39.

10 Martin JR. Troop-related multiple sclerosis outbreak in the Orkneys. F Epidemiol Community Health 1987;41. $183-4$.

11 Kurtze JF, Gudmusson KR, Bergmann S. Multiple sclerosis in Iceland: Evidence of a post-war epidemic. Neurology 1982:32:143-50.

12 Rosati G, Aiello I, Granieri E, et al. Incidence of multiple sclerosis in Macower, Sardinia 1912-1981; onset of the disease after 1950. Neurology, 1986;36:14-9.
13 King P. The Channel Islands at war. London: Robert Hale, 1991.

14 Williams ES, McKeran RO. Prevalence of multiple sclerosis in a South London Borough. BMF 1986;293:237-9.

15 Lockyer MJ. Prevalence of multiple sclerosis in five rural Suffolk practices. BMF 1991;303:347-8.

16 Roberts MHW, Martin JP, McLellan DL, et al. The prevalence of multiple sclerosis in the Southampton and South West Hampshire Health Authority. 7 Neurol Neurosurg Psychiatry. 1991;54:55-9.

17 Swingler RJ, Compston DAS. The prevalence of multiple sclerosis in South East Wales., $f$ Neurol Neurosurg sclerosis in South East

18 Mumford CJ, Fraser MB, Wood NW, Compston DAS Multiple sclerosis in the Cambridge health district in East Anglia. $f$ Neurol Neurosurg Psychiatry 1992;55: 877-82.

19 Poser CM, Pato DW, Scheinberg W, et al. New diagnostic criteria for multiple sclerosis: guidelines for research protocols. Ann Neurol 1983;13:227-31.

20 Allison RS, Millar JHD. Prevalence and familial incidence of disseminated sclerosis (A report to the Northern Ireland Hospitals Authority on the results of a three year survey). Ulster Med f 1954;23(suppl 2):5-49.

21 Jersey census 1991, States of Jersey.

22 Guernsey census 1991, States of Guernsey.

23 Alderney census 1991, States of Guernsey.

24 Millar JHD. Multiple sclerosis in Northern Ireland. In: Clifford Rose, F. ed. Clinical neuroepidemiology. Tunbridge Wells: Pitman Medical Ltd, 1980: 222-7.

25 Armitage P. Statistical methods in medical research. Oxford: Blackwell, 1971.

26 Phadke JG, Downie AW. Epidemiology of multiple sclerosis in the north-east (Grampian region) of Scotland-an update. $\mathcal{F}$ Epidemiol Community Health 1987;41:5-13.

27 French Research Group on Multiple Sclerosis. Multiple sclerosis in $\mathbf{5 4}$ twinships-concordance rate is independent of zygosity. Ann Neurol 1992;32:724-7. 